\title{
Pharmacoproteomic study of the effects of chondroitin and glucosamine sulfate on human articular chondrocytes
}

\author{
Valentina Calamia', Cristina Ruiz-Romero1', Beatriz Rocha', Patricia Fernández-Puente1, Jesús Mateos', \\ Eulàlia Montell2, Josep Vergés² and Francisco J Blanco*1
}

\begin{abstract}
Introduction: Chondroitin sulfate (CS) and glucosamine sulfate (GS) are symptomatic slow-acting drugs for osteoarthritis (OA) widely used in clinic. Despite their widespread use, knowledge of the specific molecular mechanisms of their action is limited. The aim of this work is to explore the utility of a pharmacoproteomic approach for the identification of specific molecules involved in the pharmacological effect of GS and CS.

Methods: Chondrocytes obtained from three healthy donors were treated with GS $10 \mathrm{mM}$ and/or CS $200 \mu \mathrm{g} / \mathrm{mL}$, and then stimulated with interleukin-1 $\beta$ (IL-1 $\beta) 10 \mathrm{ng} / \mathrm{mL}$. Whole cell proteins were isolated 24 hours later and resolved by two-dimensional electrophoresis. The gels were stained with SYPRORuby. Modulated proteins were identified by matrix-assisted laser desorption/ionization time-of-flight (MALDI-TOF/TOF) mass spectrometry. Real-time PCR and Western blot analyses were performed to validate our results.

Results: A total of 31 different proteins were altered by GS or/and CS treatment when compared to control. Regarding their predicted biological function, 35\% of the proteins modulated by GS are involved in signal transduction pathways, $15 \%$ in redox and stress response, and $25 \%$ in protein synthesis and folding processes. Interestingly, CS affects mainly energy production (31\%) and metabolic pathways (13\%), decreasing the expression levels of ten proteins. The chaperone GRP78 was found to be remarkably increased by GS alone and in combination with CS, a fact that unveils a putative mechanism for the reported anti-inflammatory effect of GS in OA. On the other hand, the antioxidant enzyme superoxide dismutase 2 (SOD2) was significantly decreased by both drugs and synergistically by their combination, thus suggesting a drug-induced decrease of the oxidative stress caused by IL-1 $\beta$ in chondrocytes.

Conclusions: CS and GS differentially modulate the proteomic profile of human chondrocytes. This pharmacoproteomic approach unravels the complex intracellular mechanisms that are modulated by these drugs on IL1 $\beta$-stimulated human articular chondrocytes.
\end{abstract}

\section{Introduction}

Osteoarthritis $(\mathrm{OA})$ is becoming increasingly prevalent worldwide because of the combination of an aging population and growing levels of obesity. Despite the increasing number of OA patients, treatments to manage this disease are limited to controlling pain and improving function and quality of life while limiting adverse events

\footnotetext{
* Correspondence: francisco.blanco.garcia@sergas.es

${ }^{1}$ Osteoarticular and Aging Research Lab, Proteomics Unit, Lab of Proteo-Red. Rheumatology Division, INIBIC-CHU A Coruña, As Xubias s/n, A Coruña 15006, Spain

Full list of author information is available at the end of the article
}

[1]. Effective therapies to regenerate damaged cartilage or to slow its degeneration have not been developed.

The failure of conventional treatments (analgesics or non-steroidal anti-inflammatory drugs) to satisfactorily control OA progression, combined with their frequent adverse side effects, may explain the increasing use of such SYSADOA (SYmptomatic Slow-Acting Drugs for Osteoarthritis) therapies as glucosamine sulfate (GS) and chondroitin sulfate (CS). Different clinical trials have proved that GS [2-4] and CS [5,6] are effective in relieving the symptoms of OA [7], probably due to their antiinflammatory properties. However, although these 
reports were intended to resolve and clarify the clinical effectiveness of these supplements regarding OA, they leave doubts among the scientific community and fuel the controversy [8]. The recently published results of the Glucosamine/chondroitin Arthritis Intervention Trial (GAIT) showed that, in the overall group of patients with osteoarthritis of the knee, GS and CS alone or in combination did not reduce pain effectively [9]. For a subset of participants with moderate-to-severe knee pain, however, GS combined with CS provide statistically significant pain relief compared with placebo. One possible explanation for this discrepancy may be the relative participation of inflammatory cytokines in different subpopulations; and it is also hypothesized that the effects of GS and CS are better realized in patients with more severe OA, which have greater involvement of interleukin-1beta $(\mathrm{IL}-1 \beta)[10]$.

With the aim to describe more clearly the effects of GS and CS on cartilage biology and characterize their mechanism of action, we performed proteomic analyses of articular chondrocytes treated with exogenous GS and/or CS. Most previous studies have evaluated single proteins, but have not addressed the total chondrocyte proteome. With the introduction of proteomics, it has become possible to simultaneously analyze changes in multiple proteins. Proteomics is a powerful technique for investigating protein expression profiles in biological systems and their modifications in response to stimuli or particular physiological or pathophysiological conditions. It has proven to be a technique of choice for study of modes of drug action, side-effects, toxicity and resistance, and is also a valuable approach for the discovery of new drug targets. These proteomic applications to pharmacological issues have been dubbed pharmacoproteomics [11]. Currently, many proteomic studies use two-dimensional electrophoresis (2-DE) to separate proteins [12]; we have recently used this proteomic approach to describe the cellular proteome of normal and osteoarthritic human chondrocytes in basal conditions $[13,14]$ and also under IL-1 $\beta$ stimulation [15].

To more clearly define the effects of GS and CS on cartilage biology, we performed proteomic analyses of articular chondrocytes treated with exogenous GS and/or CS. Because the treatment efficacy of these compounds appears to vary with the pathological severity of OA, we used an in vitro model employing normal human chondrocyte cultures stimulated with IL-1 $\beta$, a proinflammatory cytokine that acts as a mediator to drive the key pathways associated with OA pathogenesis [16].

\section{Materials and methods}

\section{Reagents, chemicals and antibodies}

Culture media and fetal calf serum (FCS) were obtained from Gibco BRL (Paisley, UK). Culture flasks and plates were purchased from Costar (Cambridge, MA, USA). Two-dimensional electrophoresis materials (IPG buffer, strips, and so on) were purchased from GE Healthcare (Uppsala, Sweden). IL-1 $\beta$ was obtained from R\&D Systems Europe (Oxford, UK). Glucosamine sulfate and chondroitin sulfate were provided by Bioiberica (Barcelona, Spain). Antibody against human SOD2 was obtained from BD Biosciences (Erembodegem, Belgium), antibody against $\alpha$-Tubulin from Sigma-Aldrich (St. Louis, MO, USA), antibody against human GRP78 and the correspondent peroxidase-conjugated secondary antibodies from Santa Cruz Biotechnology (Santa Cruz, CA, USA). Unless indicated, all other chemicals and enzymes were obtained from Sigma-Aldrich.

\section{Cartilage procurement and processing}

Macroscopically normal human knee cartilage from three adult donors (44, 51 and 62 years old) with no history of joint disease was provided by the Tissue Bank and the Autopsy Service at Complejo Hospitalario Universitario A Coruña. The study was approved by the Ethics Committee of Galicia, Spain. Cartilage was processed as previously described [13].

\section{Primary culture of chondrocytes}

Chondrocytes were recovered and plated in $162-\mathrm{cm}^{2}$ flasks in DMEM supplemented with 100 units $/ \mathrm{mL}$ penicillin, $100 \mu \mathrm{g} / \mathrm{mL}$ streptomycin, $1 \%$ glutamine and $10 \%$ FCS. The cells were incubated at $37^{\circ} \mathrm{C}$ in a humidified gas mixture containing $5 \% \mathrm{CO}_{2}$ balanced with air. At confluence cells were recovered from culture flasks by trypsinization and seeded onto $100 \mathrm{~mm}$ culture plates $\left(2 \times 10^{6}\right.$ per plate) for proteomic studies or six-multiwell plates $(5$ $\times 10^{5}$ per well) for further analysis (RNA/protein extraction). Chondrocytes were used at Week 2 to 3 in primary culture (P1), after making them quiescent by incubation in a medium containing $0.5 \%$ FCS for $24 \mathrm{~h}$. Verification of cell type was carried out by positive immunohistochemistry to type II collagen. Finally, cells were cultured in FCSfree medium containing glucosamine sulfate $(10 \mathrm{mM})$ and/or chondroitin sulfate $(200 \mu \mathrm{g} / \mathrm{mL})$. Two hours later, $\mathrm{IL}-1 \beta$ was added at $10 \mathrm{ng} / \mathrm{ml}$ to the culture medium. All the experiments were carried out for 24 hours. Cell viability was assessed by trypan blue dye exclusion.

\section{Two-dimensional gel electrophoresis (2-DE)}

The 2-DE technique used in this study has been previously described [13]. Briefly, $200 \mu \mathrm{g}$ of protein extracts were applied to $24 \mathrm{~cm}, \mathrm{pH}$ 3-11 NL, IPG strips by passive overnight rehydration. The first dimension separation, isoelectric focusing (IEF), was performed at $20^{\circ} \mathrm{C}$ in an IPGphor instrument (GE Healthcare) for a total of 64,000 Vhr. The second dimension separation was run on an Ettan DALT six system (GE Healthcare) after equilibra- 
tion of the strips. Electrophoresis followed the technique of Laemmli [17], with minor modifications. We used 1X Tris-glycine electrophoresis buffer as the lower buffer (anode) and 2X Tris-glycine as the upper buffer (cathode).

\section{Protein staining}

Gels were fixed and stained overnight with SYPRORuby (Invitrogen, Carlsbad, CA, USA), according to the manufacturer's protocol. After image acquisition and data analysis, 2-DE gels were stained either with Coomassie Brilliant Blue (CBB) or silver nitrate according to standard protocols [18] to allow subsequent mass spectrometry (MS) identification.

\section{2-DE image acquisition and data analysis}

SYPRO-stained gels were digitized using a CCD camera (LAS 3000 imaging system, Fuji, Tokyo, Japan) equipped with a blue $(470 \mathrm{~nm})$ excitation source and a 605DF40 filter. $\mathrm{CBB}$ and silver stained gels were digitized with a densitometer (ImageScanner, GE Healthcare). Images from SYPRO-stained gels were analyzed with the PDQuest 7.3.1 computer software (Bio-Rad, Hercules, CA, USA).

\section{Mass spectrometry (MS) analysis}

The gel spots of interest were manually excised and transferred to microcentrifuge tubes. Samples selected for analysis were in-gel reduced, alkylated and digested with trypsin according to the method of Sechi and Chait [19]. The samples were analyzed using the Matrix-assisted laser desorption/ionization (MALDI)-Time of Flight (TOF)/TOF mass spectrometer 4800 Proteomics Analyzer (Applied Biosystems, Framingham, MA, USA) and 4000 Series Explorer ${ }^{\mathrm{mm}}$ Software (Applied Biosystems). Data Explorer version 4.2 (Applied Biosystems) was used for spectra analyses and generating peak-picking lists. All mass spectra were internally calibrated using autoproteolytic trypsin fragments and externally calibrated using a standard peptide mixture (Sigma-Aldrich). TOF/TOF fragmentation spectra were acquired by selecting the 10 most abundant ions of each MALDI-TOF peptide mass map (excluding trypsin autolytic peptides and other known background ions).

\section{Database search}

The monoisotopic peptide mass fingerprinting data obtained by MS and the amino acid sequence tag obtained from each peptide fragmentation in MS/MS analyses were used to search for protein candidates using Mascot version 1.9 from Matrix Science [20]. Peak intensity was used to select up to 50 peaks per spot for peptide mass fingerprinting, and 50 peaks per precursor for MS/ MS identification. Tryptic autolytic fragments, keratinand matrix-derived peaks were removed from the dataset used for the database search. The searches for peptide mass fingerprints and tandem MS spectra were performed in the Swiss-Prot release 53.0 [21] and TrEMBL release 37.0 [22] databases. Identifications were accepted as positive when at least five peptides matched and at least $20 \%$ of the peptide coverage of the theoretical sequences matched within a mass accuracy of 50 or 25 ppm with internal calibration. Probability scores were significant at $P<0.01$ for all matches. The intracellular localization of the identified proteins was predicted from the amino acid sequence using the PSORT II program [23].

\section{Western blot tests}

One-dimensional Western blot analyses were performed utilizing standard procedures. Briefly, $30 \mu \mathrm{g}$ of cellular proteins were loaded and resolved using standard 10\% SDS-polyacrylamide gel electrophoresis (SDS-PAGE). The separated proteins were then transferred to polyvinylidene fluoride (PVDF) membranes (Immobilon P, Millipore Co., Bedford, MA, USA) by electro-blotting and probed with specific antibodies against SOD2 (1:1000), GRP78 (1:500), and the housekeeping control $\alpha$-tubulin (1:2000). Immunoreactive bands were detected by chemiluminescence using corresponding horseradish peroxidase (HRP)-conjugated secondary antibodies and enhanced chemiluminescence (ECL) detection reagents (GE Healthcare), then digitized using the LAS 3000 image analyzer. Quantitative changes in band intensities were evaluated using ImageQuant 5.2 software (GE Healthcare).

\section{Real-time PCR assays}

Total RNA was isolated from chondrocytes $\left(5 \times 10^{5}\right.$ per well) using Trizol Reagent (Invitrogen, Carlsbad, CA, USA), following the manufacturer's instructions. cDNA was synthesized from $1 \mu \mathrm{g}$ total RNA, using the Transcriptor First Strand cDNA Synthesis Kit (Roche Applied Science, Indianapolis, IN, USA) in accordance with the manufacturer's instructions, and analyzed by quantitative real-time PCR. Quantitative real-time PCR assay was performed in the LightCycler 480 instrument (Roche Applied Science) using 96-well plates. Primers for SOD2, GRP78 and the housekeeping genes, HPRT1 and RPLP0, were designed using the Universal Probe Library tool from the Roche website [24]. Primer sequences were as follows: SOD2 forward, 5'-CTGGACAAACCTCAGCCCTA-3'; SOD2 reverse, 5'-TGATGGCTTCCAGCAACTC-3'; GRP78 forward, 5'-GGATCATCAA CGAGCCTACG-3'; GRP78 reverse, 5'-CACCCAGGTCAAACACCAG-3'; HPRT1 forward, 5'-TGACCTTGATTTATTTTGCATACC-3'; HPRT1 reverse, 5'CGAGCAAGACGTTCAGTCCT-3'; RPLP0 forward, 5'TCTACAACCCTGAAGTGCTTGAT-3', PRPL0 reverse 5'-CAATCTGCAGACAGACACTGG-3'. The results 
were analyzed using the LightCycler 480 software release 1.5.0 (Roche), which automatically recorded the threshold cycle (Ct). An untreated cell sample (basal) was used as the calibrator; the fold change for this sample was 1.0. Target gene Ct values were normalized against HPRT1 and RPLP0. Data were analyzed using the $2^{-\Delta \Delta C t}$ method and expressed as fold change of the test sample compared to the basal condition [25].

\section{Statistical analysis}

Each experiment was repeated at least three times. The statistical significance of the differences between mean values was determined using a two-tailed $t$-test. $P \leq 0.05$ was considered statistically significant. In the proteomic analysis, normalization tools and statistical package from PDQuest software (Bio-Rad) were employed. Where appropriate, results are expressed as the mean \pm standard error.

\section{Results}

To assess the influence of GS and CS on the intracellular pathways of human particularcz chondrocytes, we compared five different conditions: cells before treatment (basal), IL-1 $\beta$-treated cells (control), IL-1 $\beta+$ GS-treated cells, IL-1 $\beta+$ CS-treated cells and IL-1 $\beta+$ GS + CStreated cells. Two-dimensional electrophoresis (2-DE) gels of each condition were obtained from three healthy donors (a representative image of them is shown in Figure 1). The 15 digitalized images of these gels were analyzed using PDQuest analysis software. The program was able to detect more than 650 protein spots on each gel. The matched spots (540) were analyzed for their differential abundance. After data normalization, 48 protein spots were found to be altered more than 1.5-fold in the GSand CS-treated samples (both increased and decreased compared to control condition), considering only those with a significance level above $95 \%$ by the Student's $t$-test $(P<0.05)$. These spots were excised from the gels and analyzed by MALDI-TOF and MALDI-TOF/TOF MS. The resulting protein identifications led to the recognition of 35 spots corresponding to 31 different proteins that were modulated by GS- or CS- treatment. Interestingly, some of these proteins, such as heat shock protein beta-1 (HSPB1) or alpha enolase (ENOA) were present in more than one spot, indicating that they undergo posttranslational modifications, such as glycosylation or phosphorylation. Table 1 summarizes the differentially expressed proteins identified in this proteomic analysis.

Database searches allowed us to classify these 35 proteins according to their subcellular localization and cellular function. Most of them (52\%) were predicted to be cytoplasmic, while the remaining $48 \%$ were either associated with the cell membrane (20\%), extracellular matrix $(8 \%)$, or located in subcellular organelles, including the endoplasmic reticulum (10\%), mitochondria $(5 \%)$ or nucleus (5\%) (Figure 2A). The predicted biological functions for these proteins fell into six major groups: 1) energy production; 2) signal transduction; 3) protein synthesis and folding; 4) redox process and stress response; 5) cellular organization; and 6) metabolism (Figure 2B).

\section{Proteins modulated by GS treatment}

We identified 18 different proteins that were modulated by GS (Figure 3). Fourteen of these proteins were increased compared to the control, while six were decreased. Three of these proteins were found to be positively modulated only by GS: peroxiredoxin-1 (PRDX1: redox process), HSPB1 (stress response) and collagen alpha-1(VI) chain precursor (CO6A1: cell adhesion). Most of the proteins increased by GS are involved in signal transduction pathways and in protein synthesis and folding processes (see Table 1). Interestingly, all the proteins modulated by GS treatment that are related to energy production were decreased; these include ENOA, triosephosphate isomerase (TPIS) and the pyruvate kinase isozymes M1/M2 (KPYM). Other pharmacological effects of GS involve the modulation of cellular organization processes (increase of gelsolin and decrease of actin) and redox and stress responses (decrease of mitochondrial superoxide dismutase).

\section{Proteins modulated by $\mathrm{CS}$ treatment}

CS modulated 21 different proteins (Figure 3). Only nine proteins were increased, while 14 were decreased compared to the control condition. Interestingly CS, unlike GS, seems to affect mainly energy production and metabolic pathways. Proteins related to glycolysis represent the largest functional group decreased in chondrocytes treated with CS; these included glyceraldehyde 3-phosphate dehydrogenase (G3P), fructose biphosphate aldolase A (ALDOA), phosphoglycerate mutase 1 (PGAM1), TPIS, phosphoglycerate kinase 1 (PGK1), ATP synthase subunit alpha, mitochondrial (ATPA) and KPYM. Three metabolic proteins, AK1C2, GANAB and UDP-glucose 6dehydrogenase (UGDH), were also decreased. Similar to GS treatment, many proteins modulated by CS are involved in protein synthesis and folding processes. Two proteins were modified only by CS, neutral alpha-glucosidase $A B$ (GANAB), which is involved in glycan metabolism, and septin-2 (SEPT2), a cell cycle regulator (Figure $3)$.

\section{Proteins identified as modulated by GS and CS treatment}

When administered in combination, GS and CS modified, in many cases, chondrocyte proteins synergistically. Overall, this combination modulated 31 spots corresponding to 29 different proteins, 12 of them were increased and 19 were decreased (Figure 3). These proteins are found in all the functional categories, but most 
Table 1: Human articular chondrocyte proteins modified by treatment with interleukin-1 $\beta$ (IL-1 $\beta$ ) plus glucosamine and/ or chondroitin sulfate

\begin{tabular}{|c|c|c|c|c|c|c|c|c|c|}
\hline Spot $n^{\circ}$ & & Protein name & Acc. $n^{\circ \S}$ & $\mathbf{G S}^{\ddagger}$ & $\mathbf{C S}^{\ddagger}$ & $\mathbf{G S}+\mathbf{C S}^{\ddagger}$ & Loc. ${ }^{* *}$ & $M_{\mathrm{r}} / \mathrm{p} / \S \S$ & Cellular role \\
\hline 1 & PDIA1 & $\begin{array}{l}\text { Protein disulfide-isomerase } \\
\text { precursor }\end{array}$ & P07237 & 6.54 & 5.60 & 11.24 & $\mathrm{ER}, \mathrm{CM}$ & $57.1 / 4.76$ & Protein folding \\
\hline 2 & ANXA5 & Annexin A5 & P08758 & 1.97 & 1.30 & 1.52 & $\mathrm{C}$ & $35.9 / 4.94$ & Signal transduction \\
\hline 3 & GDIR & Rho GDP-dissociation inhibitor 1 & P52565 & 2.62 & 1.03 & 2.51 & $\mathrm{C}$ & $23.2 / 5.03$ & Signal transduction \\
\hline 4 & GRP78 & $\begin{array}{l}78 \mathrm{kDa} \text { glucose-regulated protein } \\
\text { precursor }\end{array}$ & P11021 & 8.08 & 1.19 & 14.15 & $\mathrm{ER}$ & $72.3 / 5.07$ & Protein folding \\
\hline 5 & C06A1 & $\begin{array}{l}\text { Collagen alpha-1(VI) chain } \\
\text { precursor }\end{array}$ & P12109 & 4.14 & -1.96 & -1.5 & EXC & $108.5 / 5.26$ & Cell adhesion \\
\hline 6 & ACTB & Actin, cytoplasmic 1 & P60709 & -3.7 & -1.41 & -1.89 & $\mathrm{C}, \mathrm{CK}$ & $41.7 / 5.29$ & Cell motion \\
\hline 7 & HSP7C & Heat shock cognate 71 kDa protein & P11142 & 7.20 & 3.90 & 5.46 & $\mathrm{C}$ & $70.9 / 5.37$ & Protein folding \\
\hline 8 & GSTP1 & Glutathione S-transferase P & P09211 & -1.2 & -1.54 & -1.49 & C & $23.3 / 5.43$ & Detoxification \\
\hline 9 & HSPB 1 & Heat shock protein beta-1 & P04792 & -1.33 & -1.35 & -1.75 & $\mathrm{C}, \mathrm{N}$ & $22.8 / 5.98$ & Stress response \\
\hline 10 & PDIA3 & $\begin{array}{l}\text { Protein disulfide-isomerase } \mathrm{A} 3 \\
\text { precursor }\end{array}$ & P30101 & 9.59 & 9.74 & 12.50 & ER & $56.8 / 5.98$ & Protein folding \\
\hline 11 & PDIA3 & $\begin{array}{l}\text { Protein disulfide-isomerase A3 } \\
\text { precursor }\end{array}$ & P30101 & 10.24 & 5.29 & 7.13 & ER & $56.8 / 5.98$ & Protein folding \\
\hline 12 & GELS & Gelsolin & P06396 & 5.93 & 3.12 & 3.98 & $\mathrm{C}, \mathrm{CK}$ & $85.7 / 5.90$ & Actin depolymerizer \\
\hline 13 & HSPB1 & Heat shock protein beta-1 & P04792 & 1.94 & -1.25 & 1.26 & $\mathrm{C}, \mathrm{N}$ & $22.8 / 5.98$ & Stress response \\
\hline 14 & GANAB & Neutral alpha-glucosidase $A B$ & Q14697 & 1.15 & -1.56 & -1.09 & $\mathrm{ER}, \mathrm{G}$ & $106.9 / 5.74$ & CH Metabolism \\
\hline 15 & ANXA1 & Annexin A1 & P04083 & 1.56 & 1.72 & 1.90 & $\mathrm{C}, \mathrm{N}, \mathrm{CM}$ & $38.7 / 6.57$ & Signal transduction \\
\hline 16 & SEPT2 & Septin-2 & Q15019 & 1.08 & -1.51 & -1.35 & $\mathrm{~N}$ & $41.5 / 6.15$ & Cell cycle/division \\
\hline 17 & ENOA & Alpha-enolase & P06733 & 1.04 & 1.91 & 1.89 & $\mathrm{C}, \mathrm{CM}$ & $47.2 / 7.01$ & Glycolysis \\
\hline 18 & EF1G & Elongation factor 1-gamma & P26641 & -1.28 & -1.85 & -1.92 & C & $50.2 / 6.25$ & Protein synthesis \\
\hline 19 & TCPG & $\begin{array}{l}\text { T-complex protein } 1 \text { subunit } \\
\text { gamma }\end{array}$ & P49368 & -1.39 & -1.54 & -1.96 & C & $60.5 / 6.10$ & Protein folding \\
\hline 20 & DPYL2 & $\begin{array}{l}\text { Dihydropyrimidinase-related } \\
\text { protein } 2\end{array}$ & Q16555 & -1.12 & -1.45 & -1.79 & C & $62.3 / 5.95$ & Metabolism \\
\hline 21 & SODM & $\begin{array}{l}\text { Superoxide dismutase } \\
\text { mitochondrial }\end{array}$ & P04179 & -2.5 & -1.3 & -4.35 & MIT & $24.7 / 8.35$ & Redox \\
\hline 22 & PGAM1 & Phosphoglycerate mutase 1 & P18669 & -1.33 & -1.23 & -1.54 & $\mathrm{C}$ & $28.8 / 6.67$ & Glycolysis \\
\hline 23 & TPIS & Triosephosphate isomerase & P60174 & -1.69 & $-1.49^{*}$ & -1.72 & C & $26.7 / 6.45$ & Glycolysis \\
\hline 24 & ANXA2 & Annexin A2 & P07355 & 3.44 & 6.80 & 5.12 & $\mathrm{EXC}, \mathrm{CM}$ & $38.6 / 7.57$ & Trafficking \\
\hline 25 & AK1C2 & $\begin{array}{l}\text { Aldo-keto reductase family } 1 \\
\text { member } \mathrm{C} 2\end{array}$ & P52895 & -2 & -2.13 & -3.22 & C & $36.7 / 7.13$ & Metabolism \\
\hline 26 & ENOA & Alpha-enolase & P06733 & -1.96 & -1.37 & -1.92 & $\mathrm{C}, \mathrm{CM}$ & $47.2 / 7.01$ & Glycolysis \\
\hline 27 & UGDH & UDP-glucose 6-dehydrogenase & 060701 & -1.16 & -2.08 & -1.85 & $\mathrm{C}$ & $55.0 / 6.73$ & Metabolism \\
\hline 28 & ANXA2 & Annexin A2 & P07355 & 2.69 & 3.06 & 2.82 & $\mathrm{EXC}, \mathrm{CM}$ & $38.6 / 7.57$ & Trafficking \\
\hline 29 & PGK1 & Phosphoglycerate kinase 1 & P00558 & -1.14 & -2.33 & -2.32 & C & $44.6 / 8.30$ & Glycolysis \\
\hline 30 & ATPA & $\begin{array}{l}\text { ATP synthase subunit alpha, } \\
\text { mitochondrial }\end{array}$ & P25705 & -1.43 & -2.17 & -2.22 & MIT & $59.8 / 9.16$ & Respiration \\
\hline 31 & KPYM & Pyruvate kinase isozymes M1/M2 & P14618 & -1.59 & -2.44 & -2.5 & $\mathrm{C}$ & $57.9 / 7.96$ & Glycolysis \\
\hline 32 & TAGL2 & Transgelin-2 & P37802 & 1.31 & -1.09 & $-1.43^{*}$ & $\mathrm{CK}, \mathrm{CM}$ & $22.4 / 8.41$ & Structural \\
\hline 33 & PRDX1 & Peroxiredoxin-1 & Q06830 & 1.67 & -1.12 & -1.09 & $C$ & $22.1 / 8.27$ & Redox \\
\hline
\end{tabular}


Table 1: Human articular chondrocyte proteins modified by treatment with interleukin-1 $\beta$ (IL-1 $\beta$ ) plus glucosamine and/ or chondroitin sulfate (Continued)

\begin{tabular}{ccllllllll}
\hline 34 & G3P & $\begin{array}{l}\text { Glyceraldehyde-3-phosphate } \\
\text { dehydrogenase }\end{array}$ & P04406 & -1.27 & -2.04 & -2.63 & C, CM & $36.1 / 8.57$ & Glycolysis \\
35 & ALDOA & Fructose-bisphosphate aldolase A & $\mathbf{P 0 4 0 7 5}$ & -1.22 & -1.79 & -1.89 & C & $39.4 / 8.30$ & Glycolysis \\
\hline
\end{tabular}

§ Protein accession number according to SwissProt and TrEMBL databases.

${ }^{\ddagger}$ Average volume ratio vs IL-1 $\beta$, quantified by PDQuest 7.3.1. software. * Protein altered less than 1.5 -fold but with a significance level above $95 \%$ by the Student's t-test $(p<0.05)$.

** Predicted subcellular localization according to PSORTII program.

$\S \S$ Theoretical molecular weight $\left(M_{\mathrm{r}}\right)$ and isoelectric point $(\mathrm{p} /)$ according to protein sequence and Swiss-2DPAGE database.

C, cytoplasm; CK, cytoskeleton; CM, cell membrane; ER, endoplasmic reticulum; EXC, extracellular matrix; G, Golgi apparatus; MIT, mitochondria; $\mathrm{N}$, nucleus.

are involved in energy production, protein synthesis and folding. Four of these proteins are modulated only by the combined treatment: a specific isoform of HSPB1, dihydropyrimidinase-related protein 2 (DPYL2), phosphoglycerate mutase 1 (PGAM1), and transgelin-2 (TAGL2).

\section{Verification of the modulation of GRP78 and SOD2}

The results obtained by our pharmacoproteomic analysis need to be validated for differences in protein expression profiles before the biological roles of the modulated proteins are extensively studied. We selected two proteins,

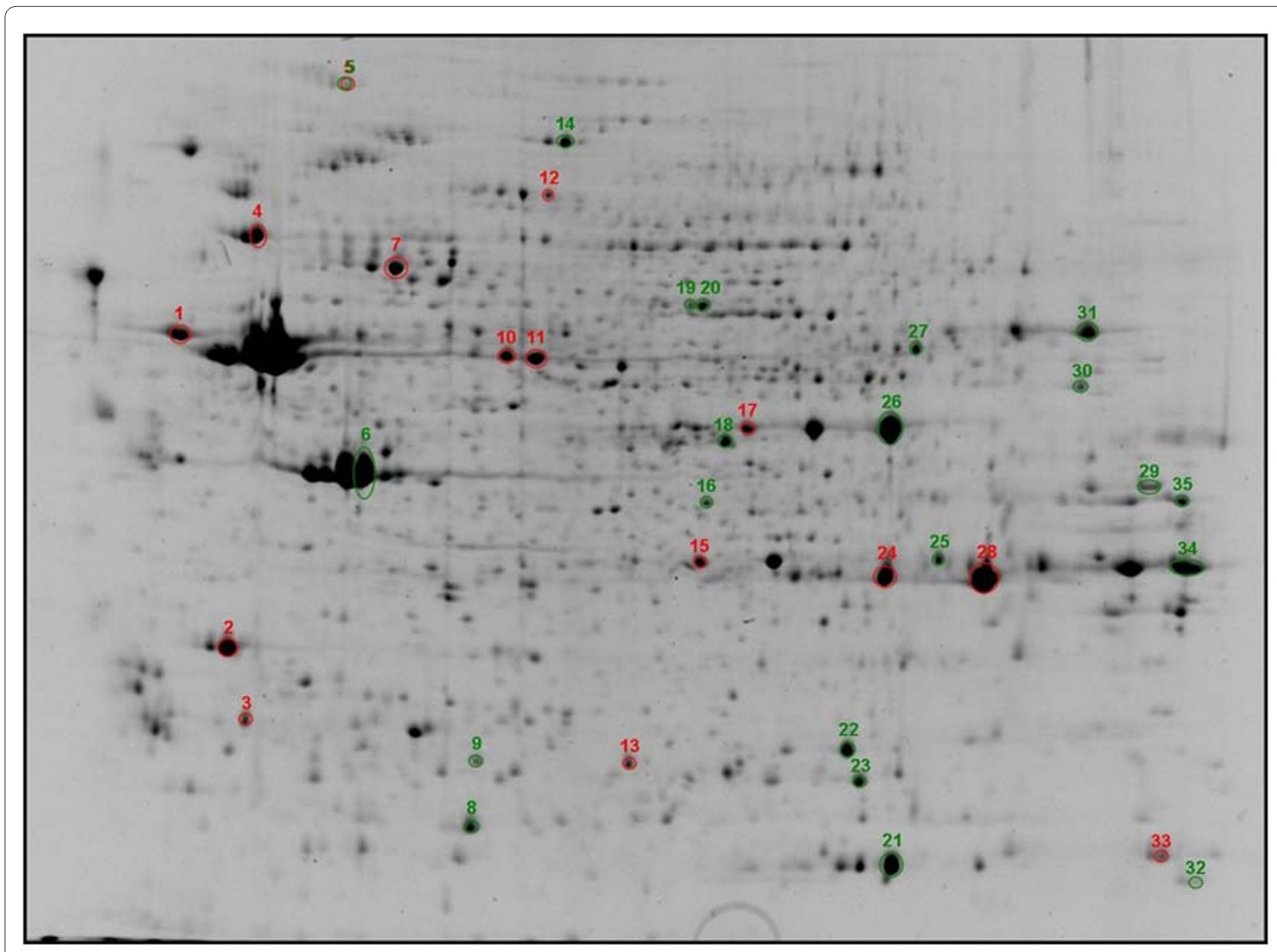

Figure 1 Representative two-dimensional electrophoresis (2-DE) map of human articular chondrocyte proteins obtained in this work. Proteins were resolved in the 3 to 11 (non linear) pH range on the first dimension, and on 10\% T gels on the second dimension. The 35 mapped and identified spots are annotated by numbers according to Table 1. 

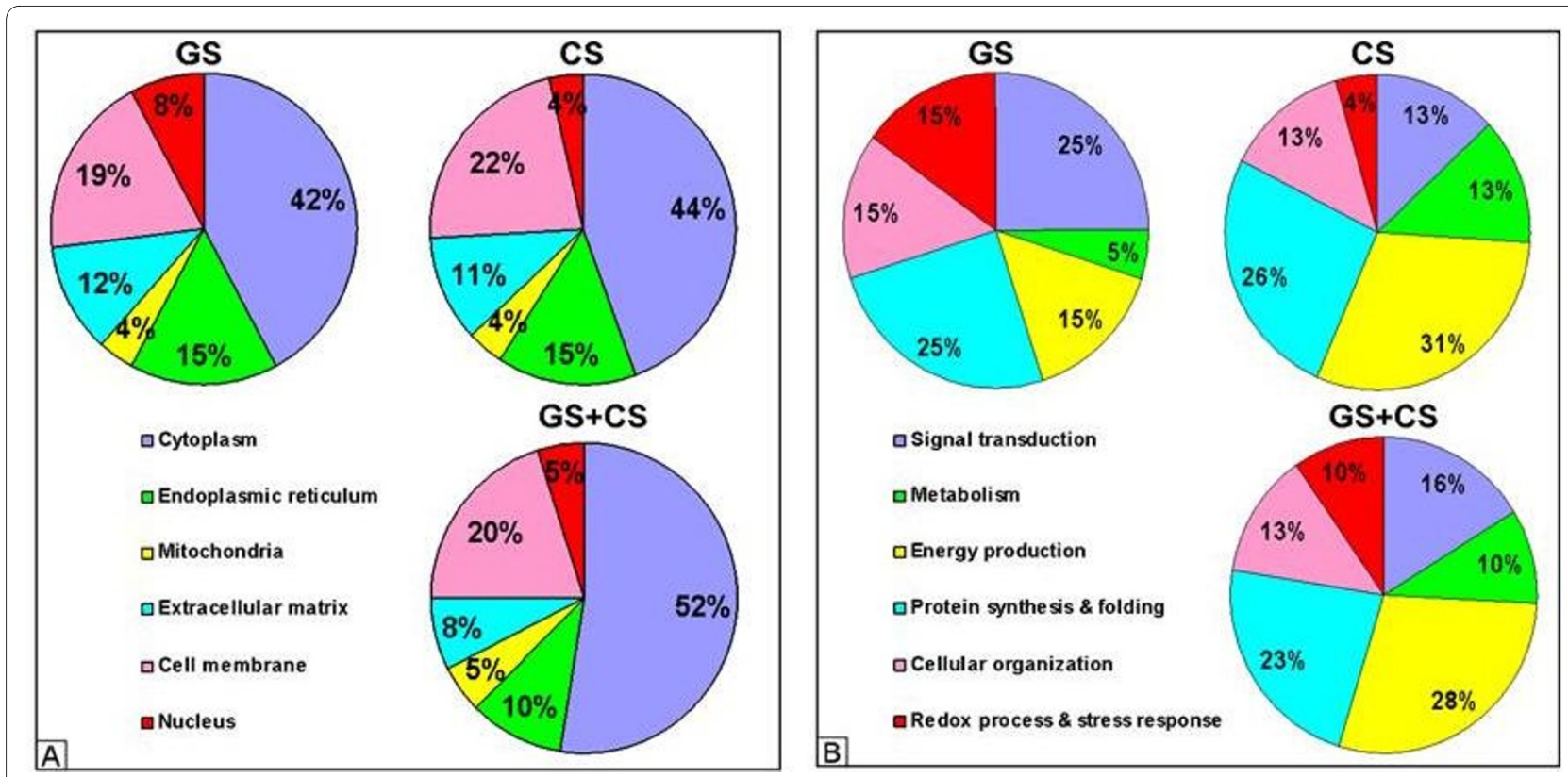

Figure 2 Subcellular localization (A) and functional distribution (B) of the GS- and/or CS-modulated proteins identified by proteomics. Database searches were used to classify these 35 proteins according to their subcellular localization and cellular function. Based on these characteristics, the proteins were assigned into six groups.

possibly involved in the OA process, on which to perform additional studies in order to verify their altered expression in GS and CS-treated chondrocytes: GRP78 and SOD2.

GRP78 was previously reported by our group to be related to OA pathogenesis [14]. We performed orthogonal studies to verify the eight-fold increase of this protein

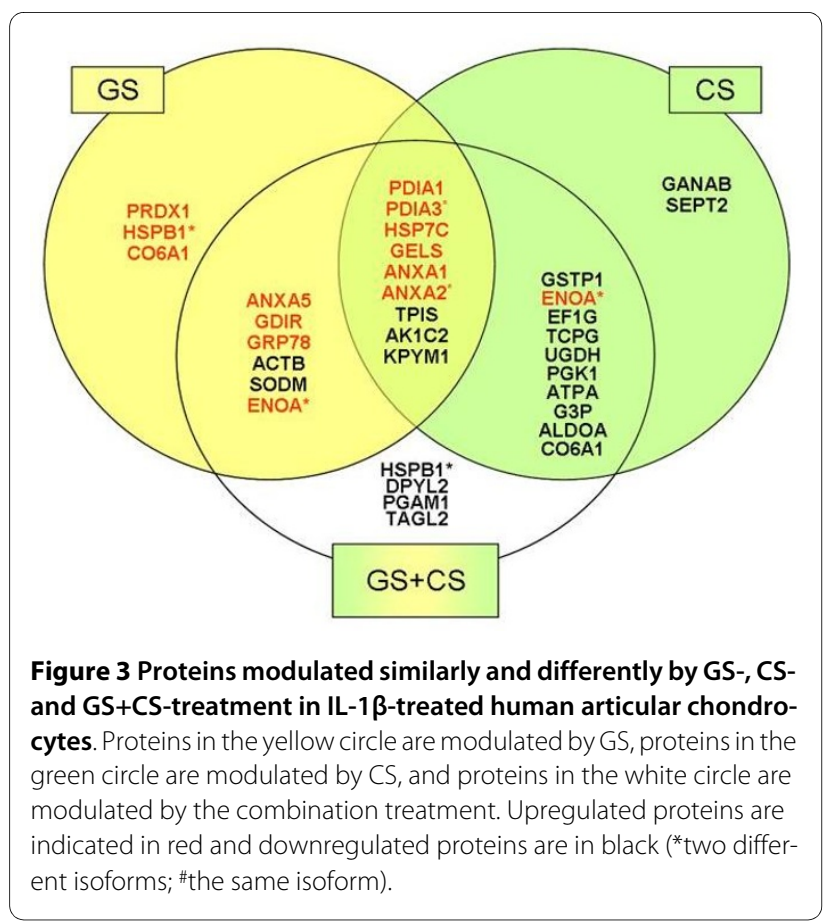

compared to the IL-1 $\beta$-treated control group observed in the proteomic analysis. Real-time PCR assays demonstrated the GS-dependent upregulation of GRP78 gene expression, showing remarkable increases of almost 30fold in GS-treated chondrocytes $(P<0.05, \mathrm{n}=6$, age range: 55 to 63 years), and even slightly higher with combined GS and CS treatment (Figure 4A). These results were confirmed at the protein level by Western blot analysis in four independent experiments. Densitometric analysis of the band intensities revealed an increase of GRP78 protein in GS- and GS + CS-treated samples that averaged 1.72-fold and 1.75-fold greater than control $(P<$ 0.05) (Figure 4B).

Mitochondrial SOD2, a protein previously reported to be related to the OA disease process [26], was decreased by GS and GS+CS treatment in our proteomic screening. To validate our data, real-time PCR analyses were carried out on RNA samples isolated from four independent experiments (Figure 5A). The results showed a significant $(P<0.001)$ up-regulation of SOD2 gene expression in IL$1 \beta$-stimulated cells, with an increase of 44-fold, and a subsequent $70 \%$ decrease in GS- and GS + CS-treated cells. We also carried out Western blot analyses to examine SOD2 modulation at the protein level. A decrease in SOD2 protein levels was evident in all donors $(\mathrm{n}=7$, age range: 51 to 72 years old). Figure $5 \mathrm{~B}$ shows data from the densitometric analysis of the blots, revealing a two-fold increase in IL- $1 \beta$-stimulated cells with subsequent $75 \%$ decrease of SOD2 in GS + CS-treated cells $(P<0.05)$. 


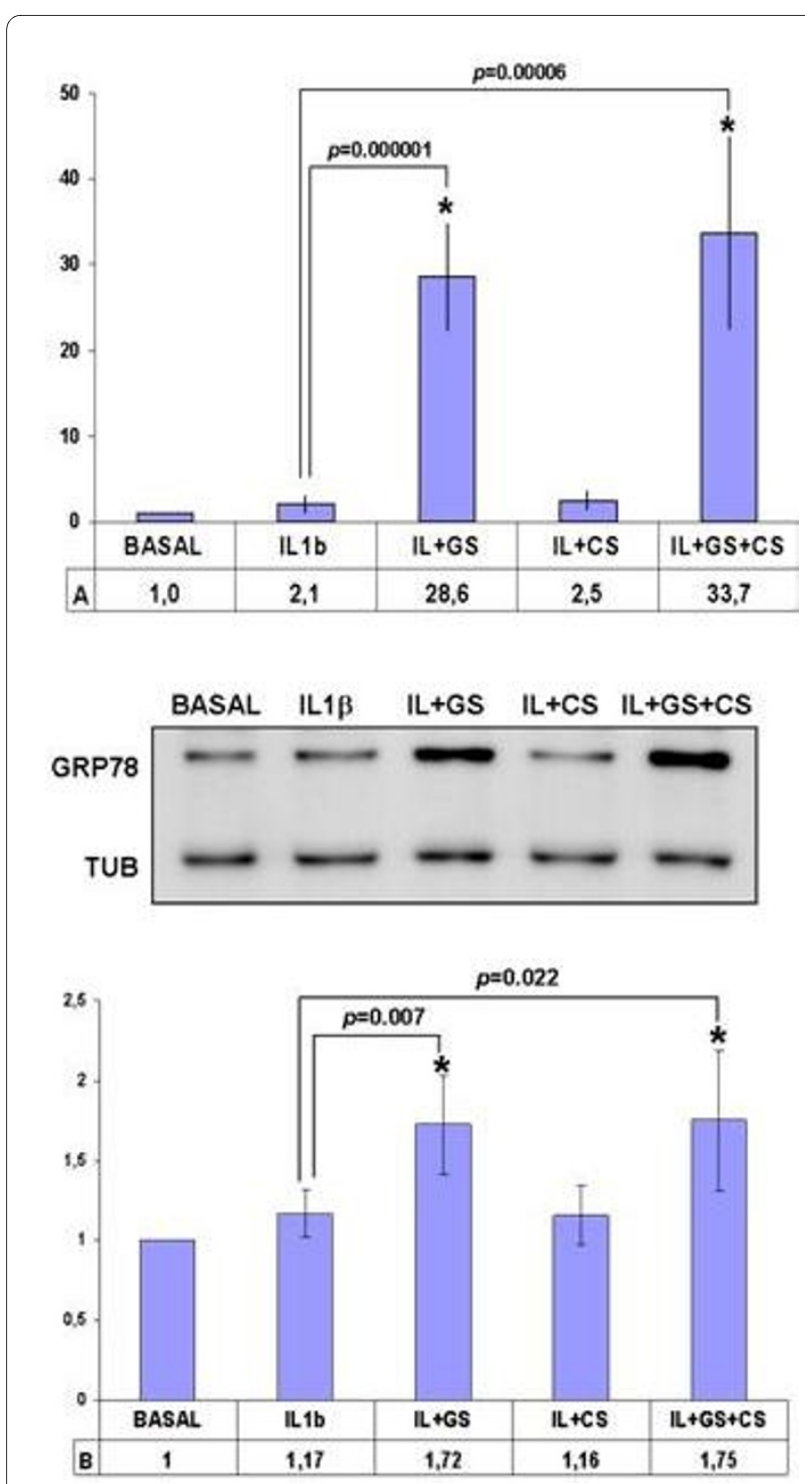

Figure 4 The $78 \mathrm{kDa}$ glucose-regulated protein precursor (GRP78) is increased by GS alone and in combination with CS. A. Overexpression values of GRP78 determined by real-time polymerase chain reaction $(\mathrm{PCR})$ analysis of cultured human articular chondrocytes treated with interleukin-1 $\beta$ (IL-1 $\beta$ ) plus GS and/or CS $\left(n=6, P<0.05^{*}\right)$. B. Western blot analysis of GRP78 protein levels in treated chondrocytes. A representative blot is shown, along with the numeric data obtained by densitometry analysis of the blots $\left(n=4, P<0.05^{*}\right)$.

\section{Discussion}

In the present work, we examined the utility of a pharmacoproteomic approach for analyzing the putative intracellular targets of glucosamine (GS) and chondroitin sulphate (CS) in cartilage cells. Using proteomic techniques, we studied the influence of these compounds, both alone and in combination, on the molecular biology of chondrocytes challenged with the proinflammatory cytokine IL-1 $\beta$.
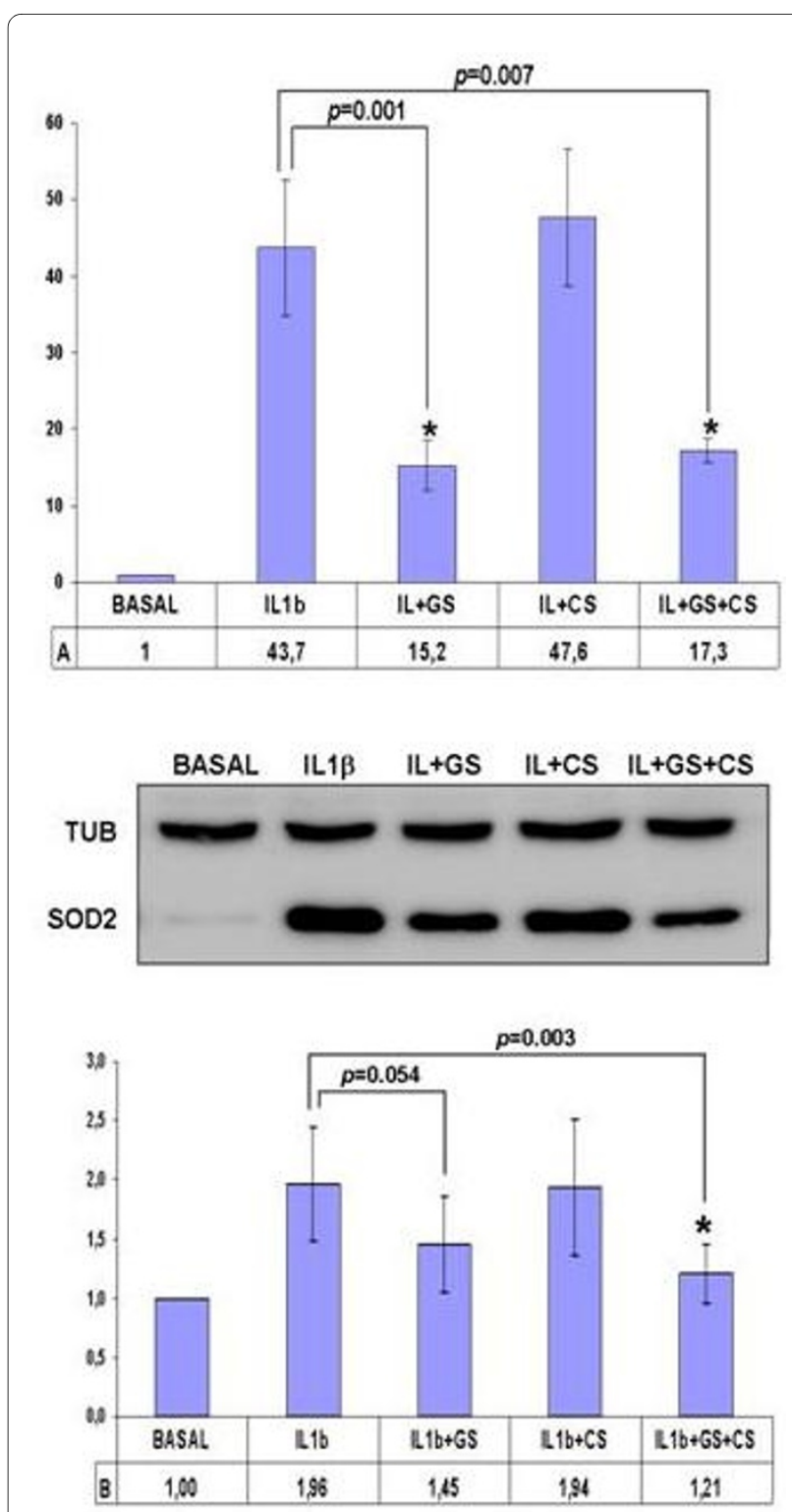

Figure 5 Mitochondrial superoxide dismutase (SOD2) is decreased by GS alone and in combination with CS. A. Underexpression values of SOD2 determined by real-time polymerase chain reaction (PCR) analysis on cultured human articular chondrocytes treated with interleukin-1 $\beta$ (IL-1 $\beta)$ plus GS and/or CS $\left(n=4, P<0.05^{*}\right)$. B. Western blot analysis of SOD2 protein levels in treated chondrocytes. A representative blot is shown, along with the numeric data obtained by densitometry analysis of the blots $\left(n=7, P<0.05^{*}\right)$.

The conditions used in this study represent supraphysiological levels of both drugs and cytokine. These concentrations, however, are included in the range of in vitro concentrations used by other laboratories, thus facilitating the comparison with other studies $[27,28]$. In our work, we chose them according to the bibliography, where a very wide range of both glucosamine and chondroitin sulfate have been used on different cell types and 
tissues $[29,30]$. We tested different concentrations of both drugs in the standardization step of the proteomic analysis (CS from 10 to $200 \mu \mathrm{g} / \mathrm{ml}$ and GS from 1 to $10 \mathrm{mM}$ ), and selected the highest concentrations in order to better unravel the molecular mechanisms that are modulated by these compounds. Moreover, in the case of glucosamine it is important to emphasize that its pharmacokinetic is modulated by the levels of glucose in the culture medium, as it utilizes glucose transporters to be taken up by the cells $[31,32]$. Since our cells are grown under high levels of glucose (DMEM, containing $25 \mathrm{mmol} / \mathrm{l}$ glucose), it is necessary to use high concentrations of glucosamine in order to appreciate its effect in the presence of high glucose. The molecular mechanisms driven with these high amounts of both drugs might not be comparable to their classical oral administration, but they can mimic a direct delivery into the joint. In this sense, it has been recently proposed that intra-articular administration of CS may provide an immediate contact with the synoviocytes and chondrocytes, as is the case in cellular culture models [33]. Furthermore, a recent study performed on cartilage explants shows how cyclic preloading significantly increased tissue PG content and matrix modulus when they are directly supplemented with high concentrations of the combination of GS and CS $(500 \mu \mathrm{g} / \mathrm{ml}$ and $250 \mu \mathrm{g} /$ $\mathrm{ml}$, respectively), resulting in a reduction of matrix damage and cell death following an acute overload [34].

All the mentioned limitations are inherent to in vitro studies, and also highlight the screening utility of proteomic approaches. Given the high complexity of these kinds of studies (and specifically the present one, in which five different conditions are evaluated), it is essential to be reminded how these approaches aim to screen for differences between the conditions that are being compared, opening the door for subsequent more exhaustive verification studies of some of these changes (which would allow both the inclusion of more samples to be analyzed and the performance of time-course or doseresponse experiments). As a proof of the act, in this work (and based on their previously described relationship with OA pathogenesis) we selected one protein that was increased (GRP78) by the drug treatment and one that was decreased (SOD2), and performed orthogonal studies on them to verify their alteration.

Despite their limitations, several in vitro studies have previously shown how CS and GS could moderate some aspects of the deleterious response of chondrocytes to stimulation with IL-1 $\beta$. In chondrocyte cultures, GS and CS diminish the IL-1 $\beta$-mediated increase of metalloproteases, $[35,36]$ the expression of phospholipase A2 [37,38] and cyclooxygenase-2, [39] and the concentrations of prostaglandin $\mathrm{E}_{2}[40]$. They also reduce the concentration of pro-inflammatory cytokines, such as tumor necrosis factor- $\alpha$ (TNF- $\alpha)$ and IL-1 $\beta$, in joints, [41] and systemic and joint concentrations of nitric oxide [42] and reactive oxygen species (ROS) [43]. All these studies showed similar results for both molecules, mainly related to their anti-inflammatory effect, while the results obtained by our pharmacoproteomic approach highlight the different molecular mechanisms affected by GS or CS. It is essential to point out that our study has been performed with chondrocytic intracellular extracts. In this context, it is difficult to identify proteins that are known to be secreted by the chondrocytes, such as metalloproteinases, cytokines or aggrecanases, which have been the focus of a recent mRNA-based analysis [44], or hyaluronan synthases, which have been newly found to be increased by CS in synoviocytes [45]. All these were also described to be modulated by GS in a previous transcriptomic study [10]. However, detection of this type of proteins in intracellular fractions by shotgun proteomics is not easily achievable because they are mainly delivered to the extracellular space after their synthesis, being those small amounts that are retained inside the cells masked by other typical cytoplasmic proteins which are more abundant [13]. Given the high dynamic range of proteins in biological systems, this problem is inherent to global screening proteomic experiments, and is only solvable employing hypothesis-driven proteomics strategies (targeted proteomics)

As mentioned before, this study is focused on the investigation of the intracellular mechanisms modulated by CS and GS, which are the background for ulterior putative changes of ECM turnover. In our work, $25 \%$ of the proteins modulated by GS are involved in signal transduction pathways, $15 \%$ in redox and stress response, and $25 \%$ in protein synthesis and folding processes, whereas CS affects mainly energy production (31\%) and metabolic pathways (13\%) by decreasing the expression levels of 10 proteins (Figure 1B). Bioinformatic analysis using Pathway Studio 6.1 software (Ariadne Genomics, Rockville, MD, USA) enabled the characterization of the biological association networks related to these differentially expressed chondrocytic proteins. A simplified picture of their interactions is showed in Figure 6. Using this analysis, we identified the biochemical pathways that may be altered when chondrocytes are treated with GS and CS.

Most of the proteins modulated by GS belong to the complex homeostatic signalling pathway known as the unfolded protein response (UPR). The UPR system is involved in balancing the load of newly synthesized proteins with the capacity of the ER to facilitate their maturation. Dysfunction of the UPR plays an important role in certain diseases, particularly those involving tissues like cartilage that are dedicated to extracellular protein synthesis. The effect of GS on molecular chaperones and the role of protein disulfide isomerases (PDIs) in the maturation of proteins related with cartilage ECM structure have 


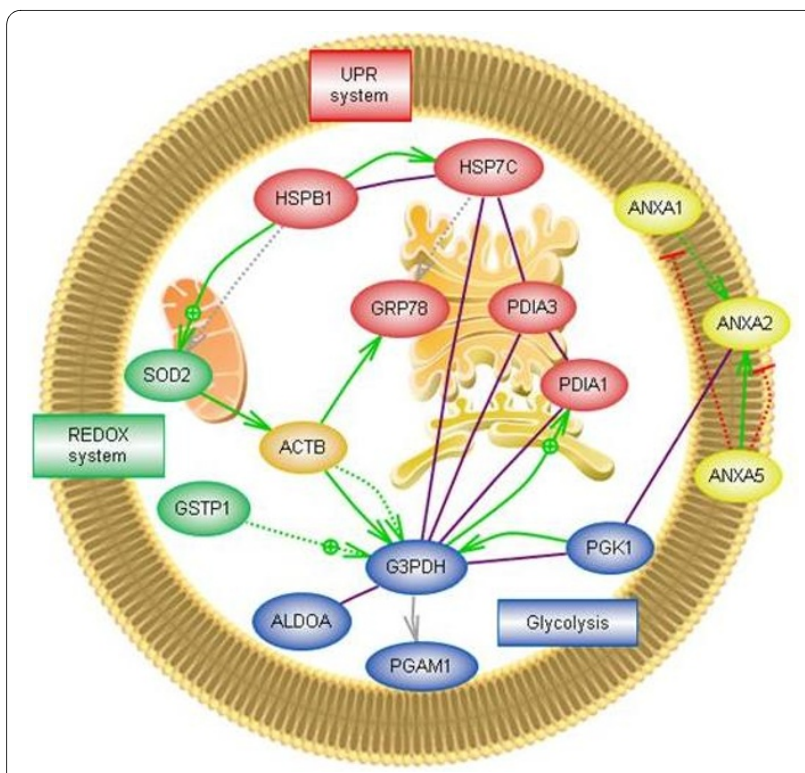

Figure 6 Pathways and networks related to chondrocyte proteins identified by proteomics as altered by GS and/or CS. Pathway Studio software was used to map the identified proteins into characterized human pathways and networks that associate proteins based on known protein-protein interactions, mRNA expression studies and other previously described biochemical interactions. Abbreviations are shown as in Table 1. Most of the proteins modulated by GS belong to the unfolded protein response (UPR) system, while CS seems to affect mainly energy production (glycolysis) and metabolic pathways.

been described [46]. PDIA3 (GRP58) is a protein on the ER that interacts with the lectin chaperones, calreticulin and calnexin, to modulate the folding of newly synthesized glycoproteins [47], whereas PDIA1 (prolyl 4hydroxylase subunit beta) constitutes a structural subunit of prolyl 4-hydroxylase, an enzyme that is essential for procollagen maturation [48]. The marked GS-mediated increase of these proteins in chondrocytes points to an elevation in ECM protein synthesis, which might be also hypothesized by the detected increase in Type IV Collagen (COL6A1, essential for chondrocyte anchoring to the pericellular matrix [49]) synthesis caused by GS.

Finally, GS remarkably increases another UPR-related protein, GRP78 (BiP), a fact that we confirmed both at transcript and protein levels. This protein is localized in the ER, and has been previously identified as an RA autoantigen [50], which was subsequently characterized by its anti-inflammatory properties through the stimulation of an anti-inflammatory gene program from human monocytes and the development of T-cells that secrete regulatory cytokines such as IL-10 and IL-4 [51]. In a previous work, we found an increase of this protein in OA chondrocytes, which might be a consequence of heightened cellular stress [14]. A number of previous reports have described the positive modulation of GS on ER proteins, including GRP78 expression [52], but this is the first time that such modulation was found to arise from GS treatment in chondrocytes; thus interestingly suggesting an specific mechanism of action for the putative antiinflammatory effect of GS in OA.

On the other hand, most proteins modulated by CS are proteins related to metabolism and energy production. It is remarkable that all except one (an enolase isoform) were decreased. In this group, we identified seven out of the 10 enzymes that directly participate in the glycolysis pathway (aldolase, triose phosphate isomerase, glyceraldehyde phosphate dehydrogenase, phosphoglycerate kinase, phosphoglyceromutase, enolase and pyruvate kinase). This suggests that, while IL- $1 \beta$ treatment tends to elevate glycolytic energy production ([15] and our observations), it is then lowered by CS (which reduces five of these enzymes) and by the combination of both drugs (which reduces all seven glycolytic enzymes). The decrease of Neutral alpha-glucosidase $A B$ (or glucosidase II, GANAB), only caused by CS alone (Figure 2), and two other metabolism-related proteins (AK1C2 and UGDH), points also to a reduction of cellular metabolism. GANAB is an ER-enzyme that has profound effects on the early events of glycoprotein metabolism, and has been recently proposed as biomarker for detecting mild human knee osteoarthritis [53].

Interestingly, only four proteins were found to be modulated by GS and CS combination but not by either of the drugs alone, whereas we observed a quantitative synergistic effect of the combination in more than a half (55\%) of the altered proteins (Table 1). One of the proteins whose decrease by both drugs alone was significant and furthermore powered by their combination is the redoxrelated protein SOD2. This protein, the mitochondrial superoxide dismutase, has substantial relevance in stress oxidative pathways and in cytokine-related diseases, such as OA [54]. We found SOD2 to be upregulated by IL-1 $\beta$ ([15] and our observations), and downregulated by GS and CS treatment, both at the transcriptional and protein levels (Real Time-PCR and Western blotting). Supporting our findings, other authors have recently reported the role of GS in counteracting the IL- $1 \beta$-mediated increase of inducible nitric oxide synthase (iNOS) and the decrease of heme oxygenase, and indicated that the influence of GS and CS on oxidative stress is a possible mechanism of action for its protective effect on chondrocytes [55].

\section{Conclusions}

Taking into account the limitations of an in vitro study, our findings provide evidence for the usefulness of proteomics techniques for pharmacological analyses. The potential application of this approach is to identify efficacy markers for monitoring different OA treatments. In this study, a number of target proteins of GS and CS have 
been described, pointing out the wide-ranging effects of these drugs on fundamental aspects of chondrocyte metabolism, but also their alternative mechanisms of action in a system model of OA.

\section{Abbreviations}

2-DE: two-dimensional electrophoresis; CDNA: complementary DNA; CS: chondroitin sulfate; $C_{t}$ : threshold cycle; DMEM, Dulbecco's modified Eagle's medium; ECM: extracellular matrix; ER: endoplasmic reticulum; FCS: fetal calf serum; GRP78: glucose regulated protein 78; GS: Glucosamine sulfate; IEF: isoelectric focusing; IL-1 3 : inteleukin-1 $\beta$; IPG: immobilized pH gradient; MALDITOF: Matrix-assisted laser desorption/ionization Time of Flight; MS: mass spectrometer; OA: osteoarthritis; PCR: polymerase chain reaction; SDS: sodium dodecyl sulphate; SOD2: superoxide dismutase 2; SYSADOA: Symptomatic Slow-Acting Drugs for Osteoarthritis; UPR: unfolded protein response.

\section{Competing interests}

EM is the Head of the Medical Area from Bioibérica, SA. JV is Medical Director of Bioibérica, SA. FJB received a grant from Bioibérica, SA to carry out this project. The authors declare no other competing interests.

\section{Authors' contributions}

VC carried out the experimental work, analysed the data and drafted the manuscript. CRR participated in study design, interpretation of data and manuscript preparation. BR helped in collecting and processing protein samples, participated in Western blot experiments and helped in statistical data analysis. PFP and $\mathrm{JM}$ carried out the mass spectrometry analysis and database search. LM and JV provided CS and GS and helped design the study. FJB conceived and coordinated the project and revised the manuscript. All authors read and approved the final manuscript.

\section{Acknowledgements}

The authors thank Ms. P. Cal Purriños for her expert secretarial assistance, and express appreciation to the Pathology Service and to Dr. Ramallal, Mrs Lourdes Sanjurjo and Mrs. Dolores Velo from the Orthopaedics Department of the CHU A Coruña for providing cartilage samples. This study was supported by grants from Fondo Investigación Sanitaria-Spain ((CIBER-CB06/01/0040); PI-08/2028); and Secretaria I+D+I Xunta de Galicia: PGIDIT06PXIC916175PN; PXIB916357PR and PGIDIT06PXIB916358PR. C. Ruiz-Romero was supported by Programa Parga Pondal, Secretaria Xeral I+D+1, Xunta de Galicia. J. Mateos was supported by Fondo Investigación Sanitaria-Spain (CA07/00243).

\section{Author Details}

'Osteoarticular and Aging Research Lab, Proteomics Unit, Lab of Proteo-Red. Rheumatology Division, INIBIC-CHU A Coruña, As Xubias s/n, A Coruña 15006 Spain and 2 Pharmacological Research Area, Scientific Medical Department. Bioibérica S.A., Plaza Francesc Macià 7, Barcelona 08029, Spain

Received: 7 April 2010 Revised: 20 June 2010

Accepted: 13 July 2010 Published: 13 July 2010

\section{References}

1. Berenbaum F: New horizons and perspectives in the treatment of osteoarthritis. Arthritis Res Ther 2008, 10:S1.

2. Reginster JY, Deroisy R, Rovati LC, Lee RL, Lejeune E, Bruyere O, Giacovelli G, Henrotin Y, Dacre JE, Gossett C: Long-term effects of glucosamine sulphate on osteoarthritis progression: a randomised, placebocontrolled clinical trial. Lancet 2001, 357:251-256.

3. Pavelka K, Gatterova J, Olejarova M, Machacek S, Giacovelli G, Rovati LC: Glucosamine sulfate use and delay of progression of knee osteoarthritis: a 3-year, randomized, placebo-controlled, double-blind study. Arch Intern Med 2002, 162:2113-2123.

4. Towheed TE, Maxwell L, Anastassiades TP, Shea B, Houpt J, Robinson V, Hochberg MC, Wells G: Glucosamine therapy for treating osteoarthritis. Cochrane Database Syst Rev 2005:CD002946.

5. Leeb BF, Schweitzer H, Montag K, Smolen JS: A metaanalysis of chondroitin sulfate in the treatment of osteoarthritis. J Rheumatol 2000, 27:205-211.

6. Kahan A, Uebelhart D, De Vathaire F, Delmas PD, Reginster JY: Long-term effects of chondroitins 4 and 6 sulfate on knee osteoarthritis: the study on osteoarthritis progression prevention, a two-year, randomized, double-blind, placebo-controlled trial. Arthritis Rheum 2009, 60:524-533

7. McAlindon TE, LaValley MP, Gulin JP, Felson DT: Glucosamine and chondroitin for treatment of osteoarthritis: a systematic quality assessment and meta-analysis. JAMA 2000, 283:1469-1475.

8. Reichenbach S, Sterchi R, Scherer M, Trelle S, Bürgi E, Bürgi U, Dieppe PA, Jüni P: Meta-analysis: chondroitin for osteoarthritis of the knee or hip. Ann Intern Med 2007, 146:580-590.

9. Clegg DO, Reda DJ, Harris CL, Klein MA, O'Dell JR, Hooper MM, Bradley JD, Bingham CO, Weisman MH, Jackson CG, Lane NE, Cush JJ, Moreland LW, Schumacher HR Jr, Oddis CV, Wolfe F, Molitor JA, Yocum DE, Schnitzer TJ, Furst DE, Sawitzke AD, Shi H, Brandt KD, Moskowitz RW, Williams HJ: Glucosamine, chondroitin sulfate, and the two in combination for painful knee osteoarthritis. NEngl J Med 2006, 354:795-808.

10. Gouze JN, Gouze E, Popp MP, Bush ML, Dacanay EA, Kay JD, Levings PP, Patel KR, Saran JP, Watson RS, Ghivizzani SC: Exogenous glucosamine globally protects chondrocytes from the arthritogenic effects of IL1beta. Arthritis Res Ther 2006, 8:R173.

11. Chapal N, Molina L, Molina F, Laplanche M, Pau B, Petit P: Pharmacoproteomic approach to the study of drug mode of action, toxicity, and resistance: applications in diabetes and cancer. Fundam Clin Pharmacol 2004, 18:413-422.

12. Gorg A, Weiss W, Dunn MJ: Current two-dimensional electrophoresis technology for proteomics. Proteomics 2004, 4:3665-3685.

13. Ruiz-Romero C, Lopez-Armada MJ, Blanco FJ: Proteomic characterization of human normal articular chondrocytes: a novel tool for the study of osteoarthritis and other rheumatic diseases. Proteomics 2005, 5:3048-3059.

14. Ruiz-Romero C, Carreira V, Rego I, Remeseiro S, Lopez-Armada MJ, Blanco FJ: Proteomic analysis of human osteoarthritic chondrocytes reveals protein changes in stress and glycolysis. Proteomics 2008, 8:495-507.

15. Cillero-Pastor B, Ruiz-Romero C, Caramés B, López-Armada MJ, Blanco FJ: Two-dimensional electrophoresis proteomic analysis to identify the normal human chondrocyte proteome stimulated by tumor necrosis factor-alpha and interleukin-1 beta. Arthritis Rheum 2010, 62:802-814.

16. Fernandes JC, Martel-Pelletier J, Pelletier JP: The role of cytokines in osteoarthritis pathophysiology. Biorheology 2002, 39:237-246. Review

17. Laemmli UK: Cleavage of structural proteins during the assembly of the head of bacteriophage T4. Nature 1970, 227:680-685.

18. Rabilloud T, Brodard V, Peltre G, Righetti PG, Ettori C: Modified silver staining for immobilized pH gradients. Electrophoresis 1992, 13:264-266.

19. Sechi S, Chait BT: Modification of cysteine residues by alkylation. A tool in peptide mapping and protein identification. Anal Chem 1998, 70:5150-5158

20. Matrix Science [http://www.matrixscience.com

21. ExPASy Proteomics Server [http://www.expasy.ch/sprot

22. UniProt Knowledgebase [http://www.ebi.ac.uk/trembl]

23. PSORT II Prediction [http://www.psort.org/

24. Universal ProbeLibrary System [http://www.roche-appliedscience.com]

25. Livak KJ, Schmittgen TD: Analysis of relative gene expression data using real-time quantitative PCR and the 2(-Delta Delta $C(T)$ ) Method. Methods 2001, 25:402-408.

26. Ruiz-Romero C, Calamia V, Mateos J, Carreira V, Martinez-Gomariz M, Fernandez M, Blanco FJ: Mitochondrial dysregulation of osteoarthritic human articular chondrocytes analyzed by proteomics: a decrease in mitochondrial superoxide dismutase points to a redox imbalance. $\mathrm{Mol}$ Cell Proteomics 2009, 8:172-189.

27. Shikhman AR, Kuhn K, Alaaeddine N, Lotz M: N-acetylglucosamine prevents IL-1 beta-mediated activation of human chondrocytes. J Immunol 2001, 166:5155-5160

28. Gouze JN, Bianchi A, Becuwe P, Dauca M, Netter P, Magdalou J, Terlain B, Bordji K: Glucosamine modulates IL-1-induced activation of rat chondrocytes at a receptor level, and by inhibiting the NF-kappa B pathway. FEBS Lett 2002, 510:166-170.

29. Tat SK, Pelletier JP, Vergés J, Lajeunesse D, Montell E, Fahmi H, Lavigne M, Martel-Pelletier J: Chondroitin and glucosamine sulfate in combination decrease the pro-resorptive properties of human osteoarthritis subchondral bone osteoblasts: a basic science study. Arthritis Res Ther 2007, 9:R117. 
30. Iovu M, Dumais G, du Souich P: Anti-inflammatory activity of chondroitin sulfate. Osteoarthritis Cartilage 2008, 16:S14-18.

31. Uldry M, Ibberson M, Hosokawa M, Thorens B: GLUT2 is a high affinity glucosamine transporter. FEBS Lett 2002, 524:199-203.

32. Windhaber RA, Wilkins RJ, Meredith D: Functional characterisation of glucose transport in bovine articular chondrocytes. Pflugers Arch 2003, 446:572-577.

33. David-Raoudi M, Mendichi R, Pujol JP: For intra-articular delivery of chondroitin sulphate. Glycobiology 2009, 19:813-815.

34. Wei F, Haut RC: High levels of glucosamine-chondroitin sulfate can alter the cyclic preload and acute overload responses of chondral explants. J Orthop Res 2009, 27:353-359.

35. d'Abusco AS, Calamia V, Cicione C, Grigolo B, Politi L, Scandurra R: Glucosamine affects intracellular signalling through inhibition of mitogen-activated protein kinase phosphorylation in human chondrocytes. Arthritis Res Ther 2007, 9:R104.

36. Chan PS, Caron JP, Orth MW: Effects of glucosamine and chondroitin sulfate on bovine cartilage explants under long-term culture conditions. Am J Vet Res 2007, 68:709-715

37. Piperno M, Reboul P, Hellio Le Graverand MP, Peschard MJ, Annefeld M, Richard M, Vignon E: Glucosamine sulfate modulates dysregulated activities of human osteoarthritic chondrocytes in vitro. Osteoarthritis Cartilage 2000, 8:207-212.

38. Ronca F, Palmieri L, Panicucci P, Ronca G: Anti-inflammatory activity of chondroitin sulfate. Osteoarthritis Cartilage 1998, 6:14-21.

39. Chan PS, Caron JP, Orth MW: Short-term gene expression changes in cartilage explants stimulated with interleukin beta plus glucosamine and chondroitin sulfate. J Rheumatol 2006, 33:1329-1340.

40. Orth MW, Peters TL, Hawkins JN: Inhibition of articular cartilage degradation by glucosamine- $\mathrm{HCl}$ and chondroitin sulphate. Equine Vet J Supp/ 2002, 34:224-229.

41. Chou MM, Vergnolle N, McDougall JJ, Wallace JL, Marty S, Teskey V, Buret AG: Effects of chondroitin and glucosamine sulfate in a dietary bar formulation on inflammation, interleukin-1 beta, matrix metalloprotease-9, and cartilage damage in arthritis. Exp Bio/ Med (Maywood) 2005, 230:255-262.

42. Chan PS, Caron JP, Rosa GJ, Orth MW: Glucosamine and chondroitin sulfate regulate gene expression and synthesis of nitric oxide and prostaglandin $\mathrm{E}(2)$ in articular cartilage explants. Osteoarthritis Cartilage 2005, 13:387-394

43. Campo GM, Avenoso A, Campo S, Ferlazzo AM, Altavilla D, Calatroni A: Efficacy of treatment with glycosaminoglycans on experimental collagen-induced arthritis in rats. Arthritis Res Ther 2003, 5:R122-131.

44. Legendre F, Baugé C, Roche R, Saurel AS, Pujol JP: Chondroitin sulfate modulation of matrix and inflammatory gene expression in IL-1betastimulated chondrocytes--study in hypoxic alginate bead cultures. Osteoarthritis Cartilage 2008, 16:105-114.

45. David-Raoudi M, Deschrevel B, Leclercq S, Galéra P, Boumediene K, Pujol JP: Chondroitin sulfate increases hyaluronan production by human synoviocytes through differential regulation of hyaluronan synthases: Role of p38 and Akt. Arthritis Rheum 2009, 60:760-770

46. Grimmer C, Balbus N, Lang U, Aigner T, Cramer T, Müller L, Swoboda B, Pfander D: Regulation of Type II Collagen Synthesis during Osteoarthritis by Prolyl-4-Hydroxylases. Am J Pathol 2006, 169:491-502.

47. Ellgaard L, Frickel EM: Calnexin, calreticulin, and ERp57: teammates in glycoprotein folding. Cell Biochem Biophys 2003, 39:223-247.

48. Kivirikko Kl, Pihlajaniemi T: Collagen hydroxylases and the protein disulfide isomerase subunit of prolyl 4-hydroxylases. Adv Enzymol Relat Areas Mol Biol 1998, 72:325-398.

49. Alexopoulos LG, Youn I, Bonaldo P, Guilak F: Developmental and osteoarthritic changes in Col6a1-knockout mice: biomechanics of type VI collagen in the cartilage pericellular matrix. Arthritis Rheum 2009, 60:771-779.

50. Corrigall VM, Bodman-Smith MD, Fife MS, Canas B, Myers LK, Wooley P, Soh C, Staines NA, Pappin DJ, Berlo SE, van Eden W, van Der Zee R, Lanchbury JS, Panayi GS: The human endoplasmic reticulum molecular chaperone $\mathrm{BiP}$ is an autoantigen for rheumatoid arthritis and prevents the induction of experimental arthritis. J Immuno/ 2001, 166:1492-1498.

51. Panayi GS, Corrigall VM: BiP regulates autoimmune inflammation and tissue damage. Autoimmun Rev 2006, 5:140-142.

52. Matthews JA, Belof JL, Acevedo-Duncan M, Potter RL: Glucosamineinduced increase in Akt phosphorylation corresponds to increased endoplasmic reticulum stress in astroglial cells. Mol Cell Biochem 2007, 298:109-123.

53. Marshall KW, Zhang H, Yager TD, Nossova N, Dempsey A, Zheng R, Han M, Tang H, Chao S, Liew CC: Blood-based biomarkers for detecting mild osteoarthritis in the human knee. Osteoarthritis Cartilage 2005, 13:861-871.

54. Afonso V, Champy R, Mitrovic D, Collin P, Lomri A: Reactive oxygen species and superoxide dismutases: role in joint diseases. Joint Bone Spine 2007, 74:324-329. Review

55. Valvason C, Musacchio E, Pozzuoli A, Ramonda R, Aldegheri R, Punzi L: Influence of glucosamine sulphate on oxidative stress in human osteoarthritic chondrocytes: effects on HO-1, p22(Phox) and iNOS expression. Rheumatology (Oxford) 2008, 47:31-35.

doi: $10.1186 / a r 3077$

Cite this article as: Calamia et al., Pharmacoproteomic study of the effects of chondroitin and glucosamine sulfate on human articular chondrocytes Arthritis Research \& Therapy 2010, 12:R138

\section{Submit your next manuscript to BioMed Centra and take full advantage of:}

- Convenient online submission

- Thorough peer review

- No space constraints or color figure charges

- Immediate publication on acceptance

- Inclusion in PubMed, CAS, Scopus and Google Scholar

- Research which is freely available for redistribution
C) BioMed Central 